\title{
On Continuous Ageing Apparatus for Alkali-Cellulose
}

\author{
By Naozo Fukaya, Shimpei Chikaraishi, Kiyoshi Ikemoto, \\ Takeshi Ninomiya and Tadamasa Kakehi \\ Member, Mitsubishi Rayon Co., Ltd.
}

\begin{abstract}
The purpose of this study is to make the conventional ageing process for alkali-cellulose into a continuous process and to reduce manufacturing cost. Several test machines have been made and studied, and the last of them has been found to satisfy all the conditions required of a continuous ageing machine. The total length of time for ageing by this machine is about 3.5 hours, and the products obtained are superior to those made by conventional processes.
\end{abstract}

\section{Introduction}

Extensive studies on the continuous preparation of viscose have been made recently with a view to lowering the production cost and to improving the quality of viscose, and the batch process has now been partially replaced by a continuous method. For example, in the steep ing, pressing and shredding processes for alkali-cellulose, continuous metheds are now adopted in place of the conventional batch process. However, the subsequent process - the ageing process-still is carried on in cans, as attempts at continuous ageing have been unsuccessful in spite of great efforts made to that end. The present article is a report on a machine which we have successfully perfected for continuous ageing of alkali-cellulose.

Several test machines have been made and studied, and the last of them, as we have said, fulfils all the conditions required of a continuous ageing machine. It consists of three parts: (1) the heating part, (2) the reacting part, and (3) the cooling part. The first and third parts are equipped with mixing blades; the second part has none. The discharge zone of each part is provided with takeout apparatus designed after careful study, and the number of revolutions of this apparatus controls the transportation of alkali-cellulose linearly. The total time for ageing by this machine is about 3.5 hours, and the products obtained are of a very high quality.

\section{Past Attempts at Continuous Ageing}

The ageing of alkiali-cellulose consists in storing shredded crumbs for a sufficient length of time to allow the accompanying air to oxidize the cellulose to a desired degree. The conventional method of ageing is to stuff alkali-cellulose into bins, or ageing cans, which are stored at various room temperatures for pericds of between 20 and 60 hours. A demand for ever greater production has stimulated attempts in Germany to speed up the ageing process and make it continuous. These attempts are reported on in detail in reports of C.I.O.S., B.I.O.S. (1) and F.I.A.T. The continuous methods of ageing referred to in these reports are:

(1) Conveyor band type (Figure I a)

(2) Rotary drum type (ex. Rotary kiln)

(3) Büttner dryer type (Figure 1 b)

These types of agers are large in volume



Fig. 1. a Conveyor type




because of large void, and are undesirable in many other respects, so they are not used in Japan. Specific reasons why they are not used can be understood from the following conditions required of an ager.

\section{Conditions Required of a Continuous Ager}

A continuous ager should make good viscose at low cost, and this requirement demands the following mechanical conditions:

(1) Easy and correct temperature control for alkali-cellulose (during heating, reacting and ccoling).

(2) Shortness of time during which alkalicellulose should stay in an ager.

(3) Machine should be simple to construct and easy to maintain and repair.

(4) Smallness of void and the smallness of the machine in volume.

(5) Gcod enlargeability.

(6) Good controllability and absence of need for a watchman.

(7) (From a production quality standpoint) Output of $\mathrm{Na}_{2} \mathrm{CO}_{3}$ should be limited and cellulose should not dry or stick.

\section{Results of Experiments Discussed}

(A) Horizontal Mixing Blade Type

An experiment was made in which several horizontal cylinders were piled and inclined slightly and miscellaneous mixing blades used, but it was found that the void should be more than 80 percent in order to obtain alkali-cellulose equal in quality to that obtainable by the conventional batch type (Figure 2).

Cylinder:

$\begin{array}{ll}\text { Inclination } & 4^{\circ} \\ \text { Steps } & 6\end{array}$

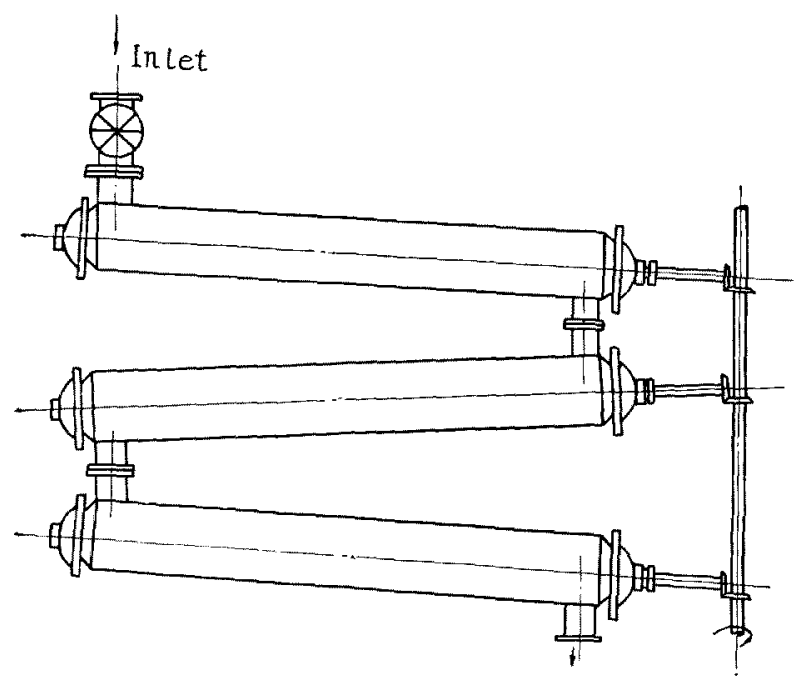

Fig. 2 Continuous Ager (Old type)
Revolutions

Void

Cylinder diameter

"l length

Top cylinder

Bottom cylinder

Ageing time:

Standard deviation

Ageing time fluctuation

$$
\begin{aligned}
& =\frac{\sigma}{\text { mean temperature } \theta m}=\frac{11.8}{360} \times 100 \\
& =3.28 \%
\end{aligned}
$$

The alkali-cellulose produced by this experiment had the composition shown in Table 1, the data being mean value every four hours.

Table 1. Cellulose \& $\mathrm{NaOH}$ Content

$$
\text { Before ageing }
$$

Cell. (\%) $31.86 \quad 32.42 \quad 32.10 \quad 31.60 \quad 3222 \quad 31.34 \quad 31.99 \quad 31.93$

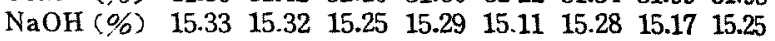
Per hour after ageing

$\begin{array}{lllllllllllll}\text { Cell. (\%) } & 31.83 & 32.25 & 32.02 & 32.21 & 32.57 & 32.05 & 32.08 & 32.22\end{array}$

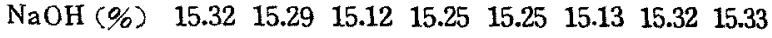

Cell, (\%) 32.5132 .24

$\mathrm{NaOH}(\%) \quad 15.18 \quad 15.19$

The mean degree of polymerization $\bar{P}$ was equal to 700 before ageing, and as shown in Table 2 after ageing. (Samples per 2 hours.)

Table 2. Variation of Mean Degree of Polymerization

\begin{tabular}{llllllll}
260 & 270 & 250 & 260 & 290 & 270 & 260 & 300 \\
\hline
\end{tabular}

The quality of yarn made from this alkalicellulose was not particularly gcod, but its spinnability was excellent.

Table 3. Property of Yarn

\begin{tabular}{ccccc} 
Denier & $\begin{array}{l}\text { Dry } \\
\text { strength } \\
(\mathrm{g} / \mathrm{d})\end{array}$ & $\begin{array}{l}\text { Wet } \\
\text { strength } \\
(\mathrm{g} / \mathrm{d})\end{array}$ & $\begin{array}{l}\text { Dry } \\
\text { elongation } \\
(\%)\end{array}$ & $\begin{array}{c}\text { Wet } \\
\text { elongation } \\
(\%)\end{array}$ \\
\hline $2.08 \sim 2.28$ & $2.24 \sim 2.44$ & $1.32 \sim 1.54$ & $14.8 \sim 16.7$ & $19.9 \sim 24.1$ \\
\hline
\end{tabular}

In view of these findings, we abondoned the experimental ager as unsuitable for industrial purposes, and made researches lcoking to improved type of machine.

(B) Improved Type

(a) Construction

In researching for an improved ager, we directed our attention to the development of a better temperature control, the reducing of fluctuations in ageing time and the lessening of void. We succeeded in devising a splendid ager. This was the last of the several machines made and studied.

It is very important that continuous apparatus be so constructed that its reaction can be separated into unit prccesses and its phe ncmencn simplified. This is true of all types of ccntinucus apparatus. In fact, we have divided the imprcved ager into three farts: 
(1) Alkali-cellulose heating part

(2) Alkali-cellulose reacting part

(3) Alkali-cellulose ccoling part

The heating and ccoling parts are differently constructed from the reacting part.

The cooling part is made larger than heating, by reason of the difference in holding time, but the two are the same in construction and have each a single bar type blade and special take-out apparatus [2] (see Figure 3.) Mixing may be done with the blade, conveying may be done by inclination, and taking out my be done with the take-up.

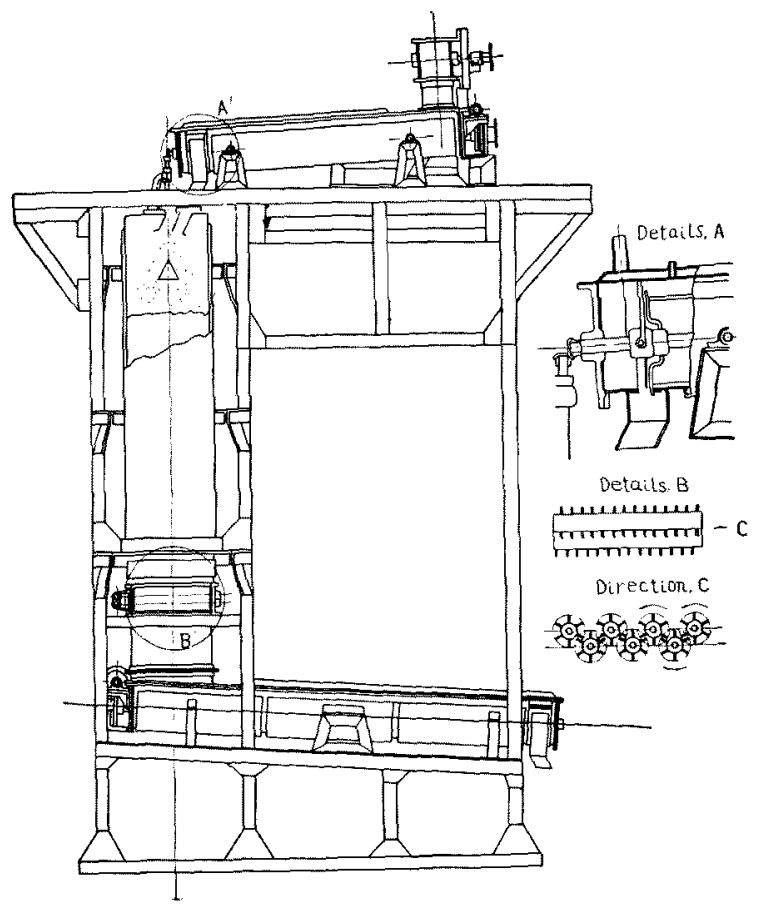

Fig. 3 Continuous ager improved type

Thanks to the bridgeability of alkali-cellulose, the amcunt of alkali-cellulcse to be delivered can be proportionally adjusted by the number of rotaions of the blade. The mixing performance is very gccd, and fluctuaticrs in ageing time are as srall as $\sigma / \theta m$ when the void is $20 \sim 40 \%$.

The overall heat transfer ccefficient of $U$ $=30 \mathrm{Kcal} / \mathrm{m}^{2} \mathrm{hr}{ }^{\circ} \mathrm{C}$ is the basis for fixing the dimensions of the apfaratus. The dimensions of the improved ager urder discussicn are:

Capacity

Inclination of heating and ccoling cylinder

Pulp 100 kgs./day

Length of heating cylinder $1385 \mathrm{~mm}$

Reacting cylinder $400 \times(1650+300)$

Length of ccoling cylinder $2085 \mathrm{~mm}$ Total height $400 \mathrm{~mm}$

Number of revolutions: Heating cylinder 13.6 r.p.m. Cooling cylinder 12 r.p.m.
Motor (with P.I.V.)

Ccoling temperature

$1 \mathrm{PP} 1, \frac{1}{2} \mathrm{P} 2$

$40^{\circ} \mathrm{C}, 35^{\circ} \mathrm{C}, 30^{\circ} \mathrm{C}$

The reacting part is a jacketed vertical cylinder with numerous parallel blades at the bottom to take off alkali-cellulose linearly by gravity[3] (void is $10 \sim 20 \%$.) The results of the experiment with this ager are shown by the following examples :

(c) Results of experiment discussed

(1) Ageing time

We measured fluctuations in ageing time in the ager by inserting red-colored alkali-cellulose between the testing materials.

Mean ageing time: heating time 10 mins. reacting time 3 hrs. ccoling time 20 mins.

Standard deviation of fluctuations $=5$ mins. Ageing time fluctuations $\frac{\sigma}{\theta \mathrm{m}}=\frac{5}{210}=2.4 \%$

(2) Fluctuations in taken-cff quantity

This is within the range of $150 \mathrm{~g} / \mathrm{min}$ (mean value $\pm 7 \%$, as shown in Figure 4 .

(3) Cellulcse temperature

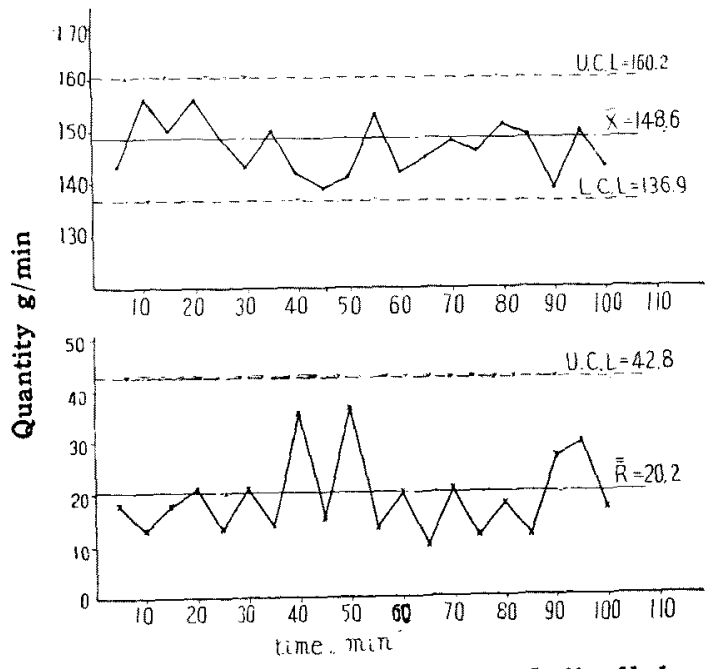

Fig. 4. Take-out quantity of alkali-cellulose

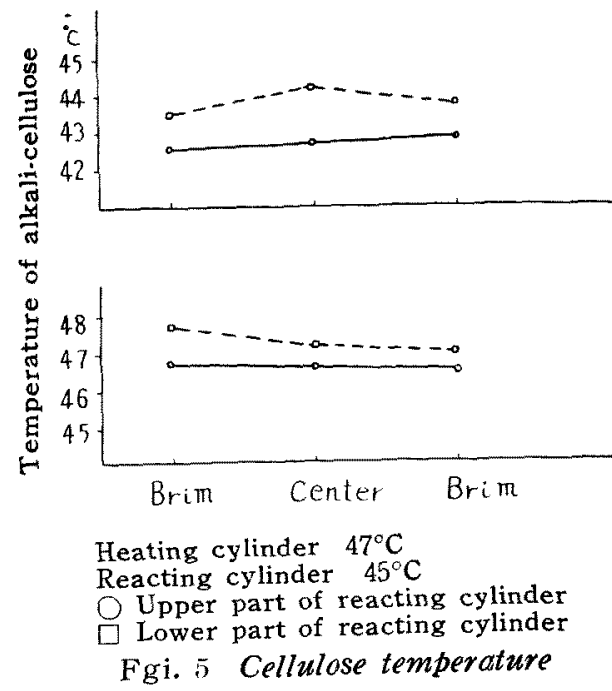



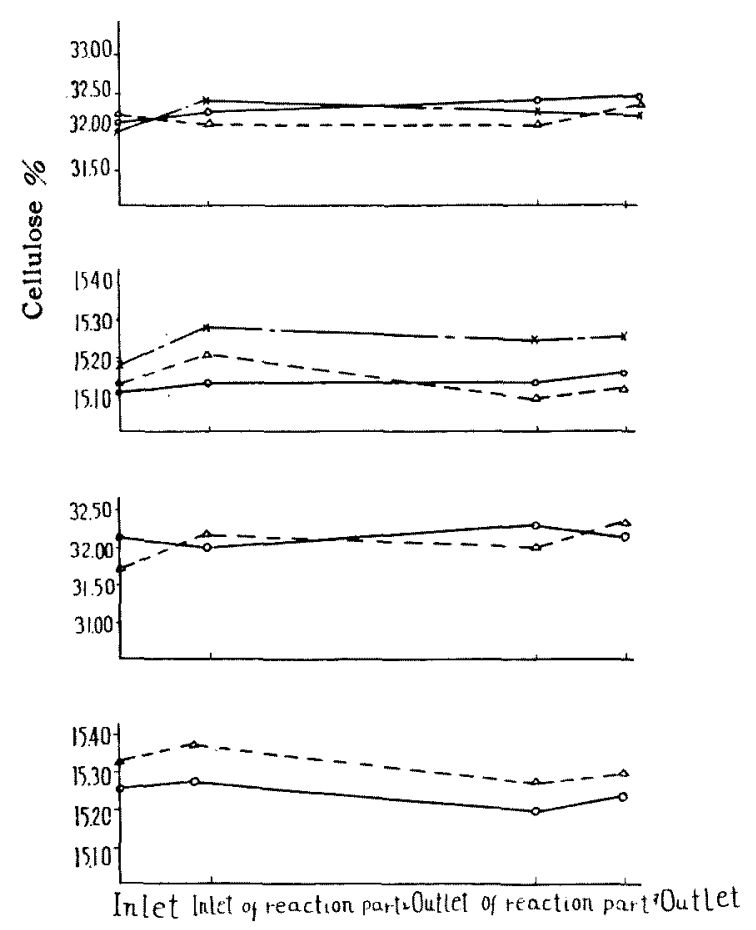

Fig. 6 Composition of alkalicellulose

This is almost constant in the heating and cooling parts, but in the reacting part it differs by about $1 \sim 2^{\circ} \mathrm{C}$ (Figure 5) due to the heat of depolymerization. Therefore, we should sepa rate the jacket into upper and lower parts, and make the temperature in the lower part $1 \sim 2^{\circ} \mathrm{C}$ higher than in the upper (Figure 5).

As we have said earlier, the cooling part has to be cooled gradually to prevent alkalicellulose from sticking. Therefore, the jacket is divided into three parts with a temperature differential of $5^{\circ} \mathrm{C}$ among them. The smaller the temperature differential is, the better the quality of the product.

(4) Fluctuations in the composition

The composition of alkali-cellulose is almost constant in the testing period, and is free from phenomenons (drying, for instance) that make the quality worse.

In the inlet and outlet of the ager, rotary valves and cellulose beds are constructed to prevent contact with air. Therefore, hardly any change in the amount of $\mathrm{Na}_{2} \mathrm{CO}_{\tilde{z}}$ is found before or after ageing.

Content of $\mathrm{Na}_{2} \mathrm{CO}_{3}$ before ageing $1.70 \sim 1.81 \%$ after ageing $1.75 \sim 1.78 \%$

(5) Mean degree of polymerization After shredding $\quad P=600$ After ageing $\quad \bar{P}=320 \sim 350$

showing nothing abnormal.

(6) Property of viscose

We xanthated and dissolved one kilogram of alkali-cellulose in a small kneader, and obtained the same viscose as by the conventional process.

\section{Conclusion}

(1) We have explained the construction of a new continuous ager for alkali-cellulose and our experiments with it. The new ager reduces to very limited proportions the defects of the conventional ager-fluctuations in ageing time and in quality.

(2) We have separated the reaction into moderate units, e.g., mixing, transportation, heating and cooling, and have adopted most suitable apparatus for each unit. We use a horizontal cylinder for heating and ccoling and vertical cylinder for ageing. Each outlet is equipped with special take-out apparatus and the amount of alkali-cellulose to be delivered can be propertionally adjusted by the number of rotations of the blade.

(3) This ager is simple in construction and can be made at low cost. Its enlargeability and controllability are excellent. For instance, dimensions of apparatus on a scale of 20 $\mathrm{t} /$ day, S.F are shown below:

$$
\begin{array}{lc}
\text { Reacting part } & 2 \mathrm{~m} \phi \times 4 \mathrm{~m} \text { (height) } \\
\text { Heating part } & 1 \mathrm{~m}(\text { breadth }) \times \\
& 0.8 \mathrm{~m} \text { (height) } \times 3.5 \mathrm{~m} \text { (length) } \\
\text { Cooling part } & 1 \mathrm{~m} \text { (breadth) } \times \\
& 1.2 \mathrm{~m} \text { (height) } \times 5 \mathrm{~m} \text { (length) }
\end{array}
$$

(4) The products obtained are superior to those made by the conventional process.

\section{References :}

[1] B.I.O.S., No. 33, The German Rayon Industry during

\begin{tabular}{|c|c|c|c|c|c|c|c|c|c|c|c|c|c|}
\hline \multicolumn{2}{|c|}{$\begin{array}{l}\text { Alkali-cellulose } \\
\text { (after shredding) }\end{array}$} & \multicolumn{2}{|c|}{ Viscose } & \multirow{2}{*}{$\begin{array}{l}\text { Viscosity } \\
\text { (Poise) }\end{array}$} & \multirow{2}{*}{$\begin{array}{l}\text { Degree } \\
\text { of } \\
\text { Xanth- } \\
\text { ation }\end{array}$} & \multirow{2}{*}{$\begin{array}{l}\text { By* } \\
\text { product }\end{array}$} & \multicolumn{4}{|c|}{$\begin{array}{l}\text { Non-dissolveing } \\
\text { fiber }\end{array}$} & \multirow{2}{*}{ K W } & \multirow{2}{*}{$\begin{array}{c}\text { Heating } \\
\text { temp. } \\
{ }^{\circ} \mathrm{C}\end{array}$} & \multirow{2}{*}{$\begin{array}{c}\text { Agent } \\
\text { temp. } \\
{ }^{\circ} \mathrm{C}\end{array}$} \\
\hline $\begin{array}{l}\text { Cell. } \\
(\%)\end{array}$ & $\underset{(\%)}{\mathrm{NaOH}}$ & $\begin{array}{l}\text { Cell. } \\
(0)\end{array}$ & $\begin{array}{c}\mathrm{NaOH} \\
(\%)\end{array}$ & & & & Ball & $\operatorname{Rod}$ & FG & G & & & \\
\hline 32.85 & 15.15 & 8.01 & 6.11 & 33 & 48 & 0.63 & 0 & 0 & 0 & 20 & 294 & 47 & 47 \\
\hline 32.85 & 15.15 & 7.91 & 6.03 & 33 & 48 & 0.74 & 0 & 10 & 0 & 30 & 206 & 47 & 47 \\
\hline 32.85 & 15.15 & 8.11 & 6.14 & 38 & 46 & 0.81 & 0 & 30 & 20 & 50 & 250 & 47 & 45 \\
\hline
\end{tabular}
the Period $(1939 \sim 1945)$.

[2] Japanese Patent, Showa 30 (1955) No.6095

[3] Japanese Patent, Showa 28 (1953) No. 2810

Table 4 Property of Viscose 